\title{
Detection of Influenza A and $B$ in Respiratory Secretions with the Polymerase Chain Reaction
}

\author{
James C. Donofrio, ${ }^{1}$ J. Donald Coonrod, ${ }^{1}$ \\ Jeffrey N. Davidson, ${ }^{1}$ and Robert F. Betts ${ }^{2}$
}

\begin{abstract}
${ }^{1}$ Departments of Medicine and Medical Microbiology and Immunology, Veterans Affairs Medical Center and University of Kentucky Medical School, Lexington, Kentucky 40536; ${ }^{2}$ Department of Medicine, University of Rochester School of Medicine and Dentistry, Rochester, New York 14642
\end{abstract}

Influenza $A$ and $B$ are RNA-containing viruses that frequently infect humans. Currently, sensitive detection of these viruses requires fresh respiratory secretions and special facilities for culture. To facilitate diagnosis of influenza, the polymerase chain reaction (PCR) was used in the present studies to detect DNA produced by reverse transcription of influenzal RNA in vaccines, tissue culture fluids, and stored respiratory secretions. Primers were directed at targets on the highly conserved segment 7 (matrix gene) of influenza $A$ (212-bp product) and $B$ (365-bp product). The primers were completely type specific. Critical variables in the assay were the concentration of pleotropic salts used during prepara. tion of samples, the use of carrier RNA and RNase inhibitors during sample preparation, and the use of optimum $\mathrm{K}^{+}$and $\mathbf{M g}^{2+}$ levels at each step. Studies of 33 patients with symptoms of viral respiratory infection whose nasal washes had been cultured and frozen for up to 1 year before assay showed that PCR provided type-specific detection of influenza with a sensitivity comparable to that of culture of the fresh secretions. The assay offers a powerful test for detection of devitalized influenza viruses and may be useful in both diagnostic work and epidemiological studies of influenza. nfluenza A and B are major causes of respiratory infection. Because the surface proteins of influenza $A$ are highly mutable, infection with this type is associated with pandemic disease in humans. In contrast, influenza $B$ causes sporadic, endemic disease. Typespecific identification of the viruses in clinical material is important because specific prophylaxis and treatment are available only for influenza $A$.

Influenza viruses are readily identified by culture of respiratory secretions, but culture requires fresh, unfrozen respiratory samples and appropriate culture facilities, which are often available only at major medical centers. Devitalized influenza virus, such as that in frozen respiratory secretions, can be detected by immunological techniques, but these methods are much less sensitive than culture. ${ }^{(1,2)}$ The polymerase chain reaction (PCR) has the potential to detect nonviable influenza virus with a sensitivity comparable to culture by amplifying DNA obtained from influenzal RNA in respiratory secretions. We report here results with a PCR assay designed to detect influenza $A$ and $B$ viruses in a variety of samples, including frozen human respiratory secretions.

\section{METHODS}

\section{Virus}

Whole virus vaccines of influenza A/Leningrad/X-91 (H3N2), A/Taiwan/ 89 (H1N1), A/Bangkok/1/79 (H3N3),
B/Ann Arbor/l/86, B/Singapore/84, and B/Yamagata/89 were kindly provided by Connaught Laboratories (Swiftwater, PA). Influenza $\mathrm{A} / \mathrm{Weiss} / 43$ and $B /$ Lee/40 were obtained from the American Type Culture Collection (Rockville, MD).

\section{Clinical Samples}

Nasal washes in normal saline solution were obtained by Dr. Robert Betts (University of Rochester) from 33 individuals with symptoms or viral upper respiratory infection in December, 1989. Viral cultures of the washes were obtained and the remainder of the samples then were stored at $-20^{\circ} \mathrm{C}$. Influenza A was cultured from washes of 14 of the patients, whereas 5 patients grew other respiratory viruses (2 adenovirus and 3 respiratory syncytial virus; 14 patients had sterile cultures. In December, 1990, the stored washes were shipped to Lexington, Kentucky, in dry ice for assay by PCR. Bronchoalveolar lavage fluids from 1 patient with culture-documented influenza $B$ and 2 patients who had sterile viral cultures were provided by Dr. Calvin Linnemann of the University of Cincinnati (Cincinnati, $\mathrm{OH}$ ).

\section{Primers}

Primers were selected from data on multiple isolates of influenza A and B on file in GenBank and the European Molecular Biology Sequence Database (Gene/Protein Sequence Database, 
Hatachi Software, Egen Co. Ltd., and America Ltd., San Bruno, California). The Oligo 4.0-2.1 program (National Biosciences, Hamel, $\mathrm{MN})^{(3)}$ was used for analysis of the primers, and particularly for estimating their potential for inter- and intramolecular bonding.

\section{Sample Processing, RNA Extraction,} and Reverse Transcription

Nine parts of denaturing solution containing $4 \mathrm{M}$ guanidinium isothio-cyanate, $25 \mathrm{~mm}$ sodium citrate, $0.5 \%$ sarcosyl, and $0.1 \mathrm{M}$ 2-mercaptoethanol was added directly to one part of frozen or unfrozen sample. Yeast tRNA was added during thawing and mixing. Phenol-chloroform extraction, followed by ethanol precipitation and vacuum centrifugation of the RNA-containing aqueous phase was carried out by the single step method of Chomczynski and Sacchi. (4)

DNA was produced from viral RNA by reverse transcription. The reaction mixture contained the following: $4 \mu \mathrm{l}$ of $5 x$ buffer (Reverse Transcriptase Buffer, Life Technologies, Inc., Bethesda Research Laboratories, Gaithersburg, $\mathrm{MD}, \mathrm{pH} 8.3$, with $250 \mathrm{~mm}$ Tris- $\mathrm{HCl}$, $375 \mathrm{mM} \mathrm{KCl}, 50 \mathrm{~mm}$ DTT, and $15 \mathrm{~mm}$ $\left.\mathrm{MgCl}_{2}\right) 100$ pmoles of complementary primer, up to $30 \mu \mathrm{g}$ of RNA (including carrier), 20 units of RNasin (Promega Corporation, Madison WI), $0.5 \mathrm{~mm}$ of each dNTP, and 200 units of reverse transcriptase (Mo-MLV; Life Technologies, Inc., BRL). The mixture was heated at $37^{\circ} \mathrm{C}$ for $1 \mathrm{hr}$ and the reaction was terminated by heating at $95^{\circ} \mathrm{C}$ for $5 \mathrm{~min}$.

\section{PCR}

For PCR, the entire volume of the reaction mixture from reverse transcription $(20 \mu \mathrm{l})$ was mixed with the following: $10 \mu \mathrm{l}$ of $10 \mathrm{x}$ buffer (PCR Buffer, PerkinElmer Cetus, Norwalk, CT, containing $100 \mathrm{~mm}$ Tris- $\mathrm{HCl}, \mathrm{pH} 8.3$, with $500 \mathrm{~mm}$ $\mathrm{KCl}, 15 \mathrm{mM} \mathrm{MgCl}_{2}$, and $0.01 \%$ gelatin), $0.1 \mathrm{mM}$ of each dNTP, 100 pmoles of each primer, and 2.5 units of Taq polymerase (Perkin-Elmer Cetus, Norwalk, CT). Final concentrations of the reactants were: $20.3 \mathrm{~mm}$ Tris- $\mathrm{HCl}, 2.1$ $\mathrm{mM} \mathrm{MgCl}_{2}, 65.5 \mathrm{mM} \mathrm{KCl}, 2 \mathrm{~mm}$ DTT, 100-200 $\mu \mathrm{M}$ for each deoxynucleotide, 1-2 $\mu \mathrm{M}$ for each primer, $1 \mathrm{mM} \mathrm{NaCl}$, $1 \%$ glycerol, and $0.0015 \mathrm{~mm}$ EDTA.

The optimal concentration of $\mathbf{M g}^{2+}$ for use in the final reaction mixture was determined by titration with primers for both influenza $A$ and $B$ and RNA extracted from A/Leningrad/X-91 and $\mathrm{B} /$ Ann Arbor/1/86 vaccines. $\mathrm{Mg}^{2+}$ concentrations of $0.6-10.0 \mathrm{~mm}$ were studied (requirements of the enzyme in the reverse transcription reaction $\mathrm{im}$ posed a minimum $\mathrm{Mg}^{2+}$ concentration of $0.6 \mathrm{~mm}$ ). With primers for influenza $A$ and $\mathrm{Mg}^{2+}$ concentrations of $0.6-1.25$ $\mathrm{mM}$, no specific PCR products were noted on gels after 40 cycles, whereas abundant specific product resulted when 1.5-2.1 mM $\mathrm{Mg}^{2+}$ was used. At 2.5-10 $\mathrm{mM} \mathrm{Mg}^{2+}$, there was declining but still discernable specific product formation; however, there was a large increase in nonspecific product formation above $2.5 \mathrm{mM} \mathrm{Mg}^{2+}$. For influenza B, specific product formation peaked above $1.0 \mathrm{mM} \mathrm{Mg}^{2+}$ with noticeable nonspecific product formation above $2.5 \mathrm{mM} \mathrm{Mg}^{2+}$. $\mathrm{A} \mathrm{Mg}^{2+}$ concentration of 1.5-2.1 mM was selected as optimal for assays in which both sets of primers were present in a single tube.

Potassium was tested in a concentration range of $40.5 \mathrm{mM}$ to $115.5 \mathrm{mM}$ with the system for influenza B. Sensitivity increased throughout this concentration range. A level of $\mathrm{K}^{+}$of 65.5 $\mathrm{mM}$ was selected for routine use.

Based on analysis of optimal denaturing, annealing, and extension temperatures, routine PCR for detection of influenza was performed for 35 cycles with denaturation at $94^{\circ} \mathrm{C}$ for $1.5 \mathrm{~min}$, annealing at $54^{\circ} \mathrm{C}$ for $2 \mathrm{~min}$, and extension at $72^{\circ} \mathrm{C}$ for $1 \mathrm{~min}$ in a PerkinElmer Cetus Thermal Cycler (Norwalk, CT). Amplification products were identified by electrophoresis on $2 \%$ agarose (DNA grade, Biorad, Richmond, CA) by use of a DNA ladder of 123 bp (Life Technologies, Inc., BRL), followed by staining with ethidium bromide (1 $\mu \mathrm{g} / \mathrm{ml}$ ) and visualization with ultraviolet light (UV Transilluminator; Fotodyne Corporation, New Berlin, WI).

\section{Hybridization with 32p-labeled Probe}

DNA was denatured by shaking the submerged gel for $1 \mathrm{hr}$ in 2 volumes of $1.5 \mathrm{M} \mathrm{NaCl}$ and $0.5 \mathrm{M} \mathrm{NaOH}$. The gel was neutralized for $1 \mathrm{hr}$ in $1 \mathrm{M}$ Tris- $\mathrm{HCl}$ (pH 8.0) in $1.5 \mathrm{M} \mathrm{NaCl}$. After Southern transfer, ${ }^{(5)}$ products of PCR on nitro- cellulose filters were air-dried and heated at $80^{\circ} \mathrm{C}$ for $2 \mathrm{hr}$. Probes to the inner region of the amplification target were end-labeled with ${ }^{32} \mathrm{P}$ and hybridization was carried out as described elsewhere. ${ }^{(6-8)}$

\section{Sequencing of PCR Products}

Sequencing was carried out with an asymmetric PCR reaction in which Taq polymerase was used to incorporate fluorescently labeled terminator dideoxynucleotides (TAQ Cycle Sequencing Kit; Applied Biosystems, Foster City, CA). The sequence of the DNA was determined by use of DNA sequencing gels and a 373 DNA sequencer (Applied Biosystems, Foster City CA). PCR primers and hybridization probes served as primers for sequencing. PCR products were sequenced without cloning and in both directions.

\section{RESULTS}

\section{Primers}

The surface proteins of influenza A characteristically show genetic drift, and for this reason the more stable matrix gene ${ }^{(9)}$ was selected for amplification by PCR. The primers chosen were two unique sequences $(A 1,25$ mer; A2, 23-mer) that defined the boundaries of a highly conserved target of 212 bases on segment 7 of A/Bangkok/1/79 (H3N2) (Fig. 1) (AC\# KO1140). ${ }^{(10)}$ A search of the pertinent files on influenza in the database indicated primer A1 had 100\% homology with 5 of 9 available sequences [i.e., A/Udorn/72 (H3N2) (AC\# JO2167), A/ Camberra/77 (H3N2) (AC\# JO2097), $\mathrm{A} / \mathrm{Ri} / 5 / 57$ (H2N2) (AC\# JO2155), A/ Loyang/4/57 (H1N1) (AC\# JO2128), and A/Fort Warren/50] (H1N1) (AC\# JO2125)] and at least $94 \%$ homology with the remaining sequences in the file [A/Puerto Rico/34 (H1N1) (AC\# XO5905), A/WSN/33 (H1N1) (AC\# M19374), A/Rostock/34 (H1N1) (AC\# M12699), and A/Mallard/NY/78 (H2N2) (AC\# M12699)]. The introduction of a single nucleotide degeneracy in $\mathrm{A} 1$ (adenosine for thymidine at position 124) provided $100 \%$ homology with all 10 influenza $A$ isolates in the database when both the original and degenerate forms of the primers were used in PCR.

The A2 primer selected (Fig. 1) was 
INFLUENZA A/BANGKOK/1/79, SEGMENT 7
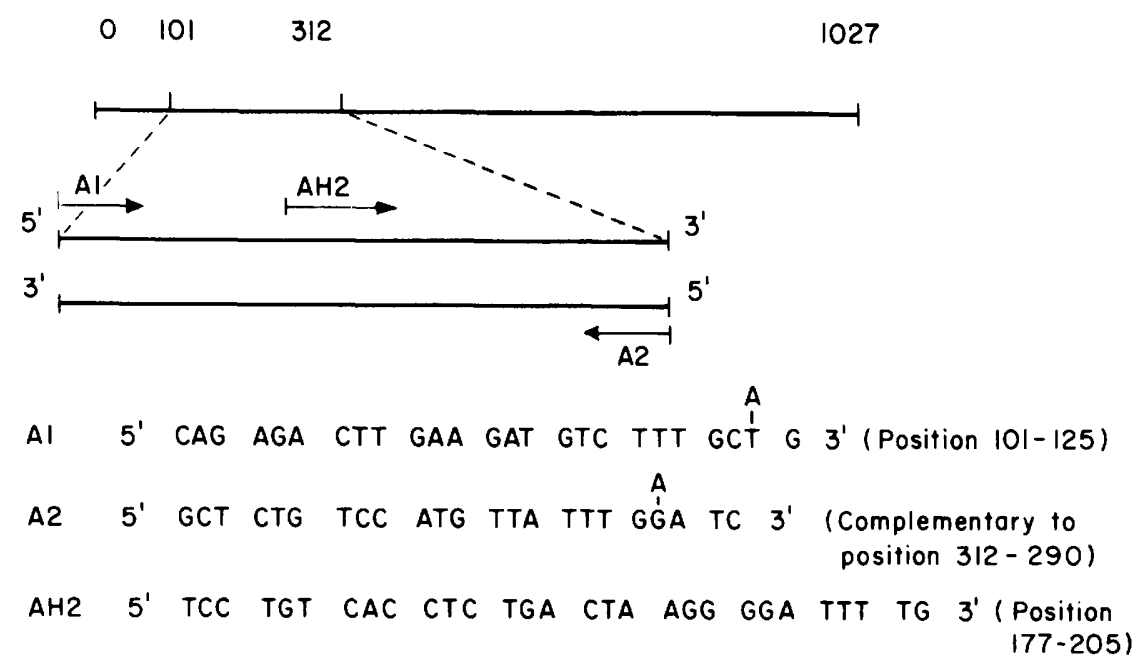

FICURE 1 Schematic representation of segment 7 (matrix gene) of influenza A/Bangkok/1/79 showing the position of two primers, A1 and A2, used for amplification of a target of 212 bases by PCR. To maximize homology with known influenza $A$ isolates, each primer was used in PCR in combination with a degenerate form containing adenosine (as illustrated). $\mathrm{AH} 2$ is the structure of the hybridization probe of the inner region of the PCR target.
$100 \%$ homologous with $\mathrm{A} /$ Bangkok/1/ 79 and A/Udorn/72 (AC\# JO2167). By substitution of adenosine for guanosine at position 320 (Fig. 1), a degenerate form was created which had $100 \%$ homology with $\mathrm{A} /$ Puerto Rico/34 (AC\# JO2145) and A/WSN/33 (AC\# M193), and the homology for A/Rostock/34 (AC\# XO5905) was increased from $91 \%$ to $96 \%$. The homology of both forms of primer A2 for A/Mallard/NY/78 (AC\# M12699) was $87 \%$.

To permit assay of both influenza $\mathrm{A}$ and $B$ in the same tube for the PCR, primers for influenza B were selected that had minimum molecular bonding with $\mathrm{A} 1$ and $\mathrm{A} 2$ and gave a larger product size (365 bases) than that of influenza $\mathrm{A}$. The target selected was position 100-464 on the matrix gene of segment 7 of influenza $\mathrm{B} /$ Lee/40 (AC\# J02094) (Fig. 2). ${ }^{(11)}$ The primers for this target (B1, 23-mer; B2B, 26-mer) were $100 \%$ homologous with the three isolates of influenza $B$ in the database [i.e., B/Lee/40, B/Ann Arbor/1/86 (AC\# M20175-6), including wild-type and

\section{INFLUENZA B/LEE/40, SEGMENT 7}

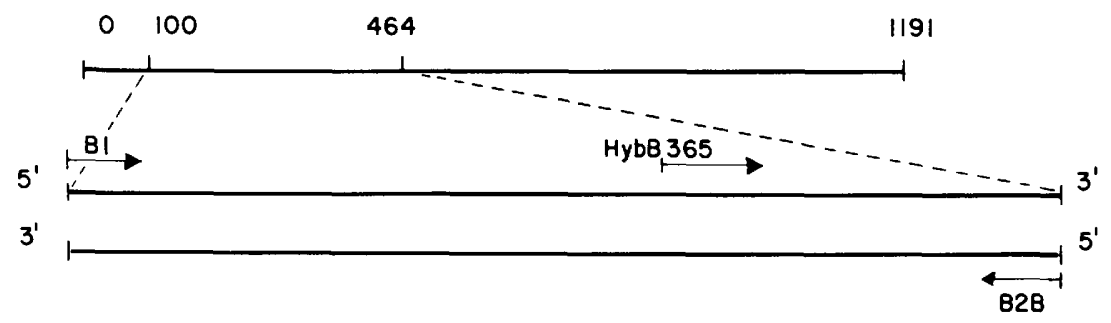

$$
\begin{aligned}
& \text { B1 5' G AAA AAT TAC ACT GTT GGT TCG GTG 3' (Position 100-124) } \\
& \text { B2B 5' AG CGT TCC TAG TTT TAC TTG CAT TGA } 3^{\prime} \text { (Complementary to } \\
& \text { position 464-439) } \\
& \text { HybB365 5' TTC TAG CTG AGA GAA AAA TGA GAA GAT GT 3'(Position } \\
& \text { 314-342) }
\end{aligned}
$$

FICURE 2 Schematic representation of segment 7 (matrix gene) of influenza B/Lee/40 showing the position of two primers, B1 and B2B, used for amplification of a target of 365 bases by PCR. HybB365 was used as a radiolabeled probe of the inner region of the target. cold-adapted viruses, and $\mathrm{B} /$ Singapore/ 79 (AC\# M14909)]. Therefore, the use of degenerate primers was unnecessary.

The potential for cross-reactivity between primers for influenza $A$ and $B$ was studied. A search for the 100 best homologies to segment 7 of $B /$ Lee/40 indicated that the B1 primer had only $44 \%$ homology with 5 of 7 isolates of influenza $\mathrm{A}$. It had only $40 \%$ homology with $\mathrm{A} /$ Rostock/34 (AC\# X05905) and $48 \%$ homology with A/USSR/90/ 77 (H1N1) (AC\# K01330). Similar results were obtained with primer B2B, where homologies for all isolates were less than $43 \%$. Homologies between $\mathrm{A}$ primers and influenza B sequences were all below $50 \%$.

\section{Detection of Influenza A}

RNA was extracted from influenza vaccine (A/Leningrad/x-91), from monkey kidney cell cultures infected with $\mathrm{A} /$ Weiss/43, and from nasal washes of a patient with culture-proven influenza (H1N1 isolate of influenza A), as well as a variety of controls. Viral DNA was produced by reverse transcription with the A2 primer, and PCR was then performed for 35 cycles. The amplification products and controls were electrophoresed on $2 \%$ agarose, stained with ethidium bromide and visualized with ultraviolet light. Results (Fig. 3) showed that products of about $212 \mathrm{bp}$ were obtained with influenza $A$ vaccine, with infected monkey kidney cells, and with nasal secretions of a patient infected with influenza A. No such products were obtained with various controls, including samples containing all reactants except reverse transcriptase (Fig. 3) and samples containing influenza $A$ but reacted with primers for influenza $B$ rather than $A$ (data not shown). The specificity of the products of 212 bp was established with a ${ }^{32}$ P-labeled probe (Fig. 3).

\section{Detection of Influenza B}

RNA was extracted from influenza vaccine (B/Yamagata/89), monkey kidney cells infected with $B / L e e / 40$, bronchoalveolar lavage fluid of a patient with culture-documented influenza B, and a variety of controls. After reverse transcription with B2B, PCR, and gel electrophoresis, amplification products of the expected size (365 bp) were found with the samples containing in- 


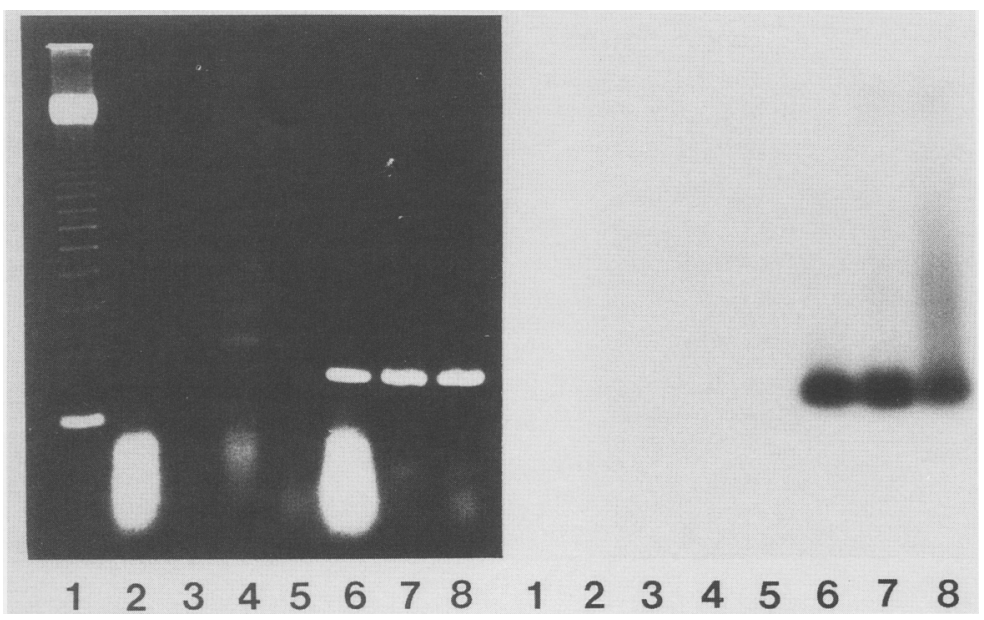

FICURE 3 (Left) Amplification products of influenza A on gels stained with ethidium bromide. (Lane 1) DNA "sizing" ladder (123 bp); (lane 2) nasal washes from a patient without influenza; (lane 3) influenza A-infected kidney cells as in lane 7 but without reverse transcriptase; (lane 4) uninfected monkey kidney cells; (lane 5) vaccine as in lane 8 but without reverse transcriptase; (lane 6) nasal wash from a patient with culture-documented influenza A; (lane 7) monkey kidney cells infected with A/Weiss/43; (lane 8) whole virus vaccine, A/Leningrad/x-91. (Right) Autoradiogram of the gel after Southern transfer and hybridization with a ${ }^{32}$ P-labeled probe, $\mathrm{AH} 2$, of the inner region of the influenza $\mathrm{A}$ target.

\section{Sequencing of Specific Products}

Sequenclng confirmed that the size of the specific PCR product of influenza A (H1N1) in infected nasal secretions was $212 \mathrm{bp}$. The size of the product of B/Ann Arbor/1/86 vaccine was confirmed as $365 \mathrm{bp}$. The sequence of the product for influenza A differed from the model sequence (i.e., A/Bangkok/ 79) by 3 nucleotides, whereas the products of influenza B/Ann Arbor/l/86 differed from the model sequence (B/Lee/40) by 20 nucleotides.

\section{Clinical Trial of PCR in Influenza A}

Frozen nasal washes were available from 33 patients who had had symptoms of viral respiratory infection and viral cultures taken approximately 1 year earlier. Disassociation buffer was added directly to the frozen samples and they were assayed for both influenza A and B in PCR. Of 14 patients whose washes grew influenza A, 13 gave products of about $212 \mathrm{bp}$ in PCR fluenza B (Fig. 4). Negative controls (Fig. 4) included samples with influenza $B$ and all reactants except reverse transcriptase or those reacted with A primers rather than B primers. Bronchoalveolar lavage fluids from 2 patients whose viral cultures were negative for influenza were negative in PCR (data not shown). An autoradiogram with a 32 P-labeled probe (HybB365) confirmed the specificity of all products of 365 bp as influenza B (Fig. 4).

\section{Simultaneous Detection of Influenza $A$ and $B$ in $a$ Single Tube}

Samples of DNA derived from influenza $A / T a i w a n / 89$ vaccine and influenza B/Ann Arbor/1/86 vaccine were mixed in a single tube containing primers $\mathrm{A} 1, \mathrm{~A} 2, \mathrm{~B} 1$, and $\mathrm{B} 2 \mathrm{~B}$ and reacted in PCR. A tube containing DNA of A/Taiwan/89 vaccine and primers $A 1$ and $A 2$ and a similar tube with DNA of B/Ann Arbor/1/86 and the B1 and $\mathrm{B} 2 \mathrm{~B}$ primers were assayed as positive controls. Results (Fig. 5) showed that the tube with influenza $A$ and $B$ and both sets of primers yielded products of about $212 \mathrm{bp}$ and $365 \mathrm{bp}$, indicating independent amplification of the targets of influenza A and B (Fig. 5).

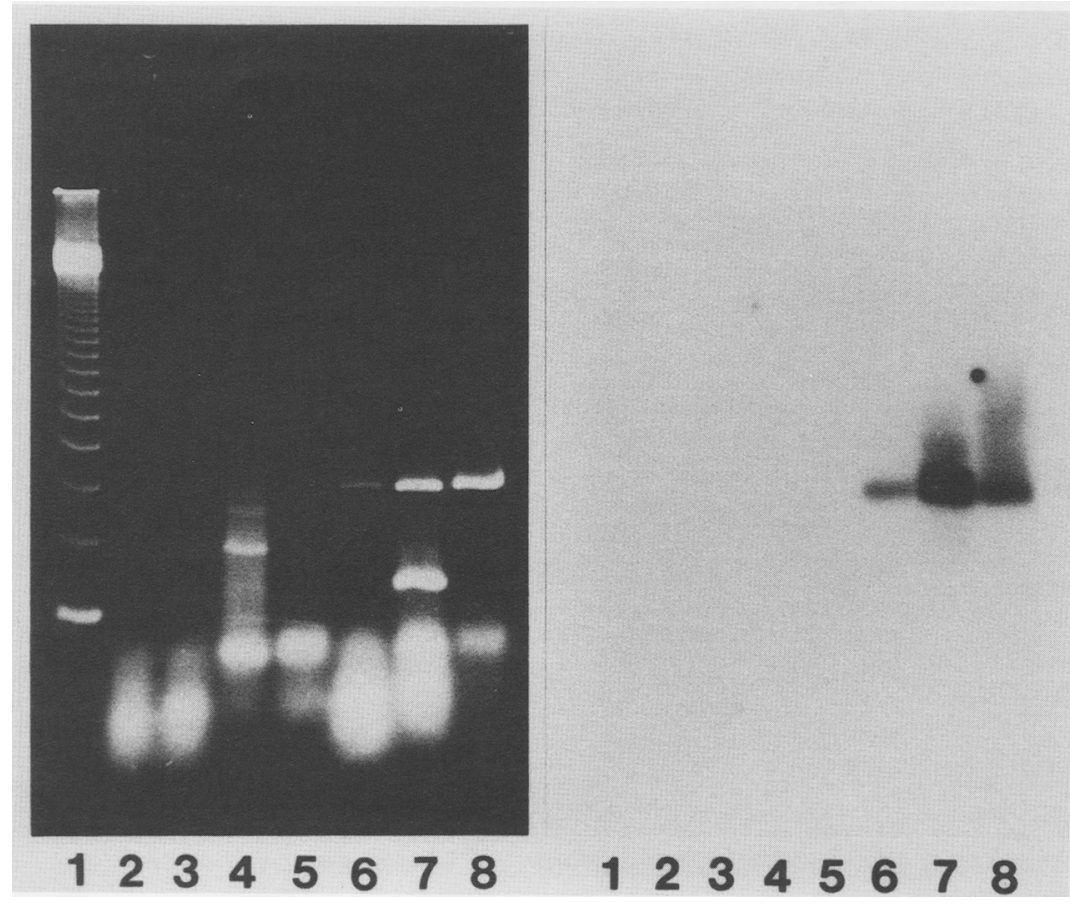

FICURE 4 (Left) Ethidium bromide-stained gel with amplification products of PCR of influenza B. (Lane 1) 123-bp ladder; (lane 2) lung washes from a patient with culturedocumented influenza B but with influenza A primers substituted for B primers; (lane 3) lung washes as in lane 2 with $A$ primers but without reverse transcriptase; (lane 4) uninfected monkey kidney cells; (lane 5) B/Yamagata whole virus vaccine with B primers but without reverse transcriptase; (lane 6 ) lung washes from a patient with culture-documented influenza B with B primers; (lane 7) monkey kidney cells infected with B/Lee/40; (lane 8) B/Yamagata vaccine. (Right) Autoradiogram of the gel after Southern transfer and hybridization with a 32 -labeled probe to influenza B, HybB365. 


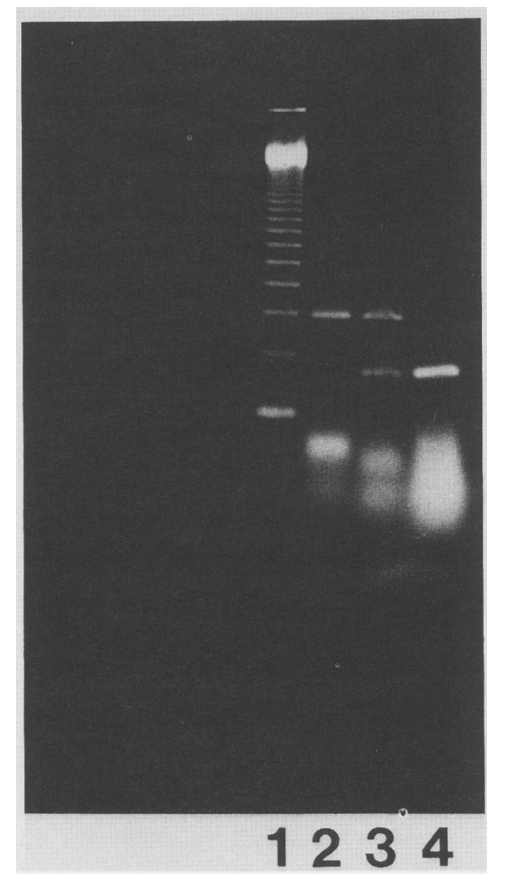

FIGURE 5 Ethidium bromide-stained gel with amplification products of A/Taiwan/89 and influenza B/Ann Arbor/1/86. PCR of the two viruses was performed separately with type-specific primers (lanes 2 and 4 , respectively) or with both viruses together in the same reaction tube with both sets of primers (lane 3). The sizing ladder is in lane 1.

and the specificity of the products was established by use of the ${ }^{32}$ P-labeled probe for type A influenza (AH2) (Table 1). Washes of 5 patients that had grown other respiratory viruses (2 adenovirus and 3 respiratory syncytial virus) gave no such products. Washes of the remaining 14 patients whose cultures had been sterile were negative for both influenza A and B in PCR, except in 2 cases. Results with these 2 individuals showed products with strong bands of $212 \mathrm{bp}$, and these products reacted strongly with the AH2 probe for influenza $A$. The findings suggested that PCR could detect influenza A in some cases where cultures failed to yield the virus.

\section{DISCUSSION}

In the present studies, a target on segment 7 (matrix gene) of influenza A was used for amplification in PCR. There is frequent antigenic variation in the envelope proteins of influenza $\mathrm{A}$, whereas the sequence of the matrix gene is more conserved. To obtain maximum homology of the target with existing sequences for influenza $A$ in the database, a single degeneracy was introduced into the $A 1$ and $A 2$ primers. This maneuver has been used to broaden the reactivity of primers in other systems. ${ }^{(12)}$ Here, it not only broadened the potential reactivity of primers and desired targets, but also may have decreased dimer formation in the case of the $A 2$ primer. With the original A2 primer, dimer formation resulted in a molecular species with significant complementarity at the 3 ' ends:

$$
\begin{aligned}
5^{\prime} \text {.GCTC - - GATC-3' } \\
:::: \\
3^{\prime} \text {-CTAG - . - CTCG-5' }
\end{aligned}
$$

The introduction of the degeneracy into $\mathrm{A} 2$ decreased the stability of this dimer as follows:

$$
\begin{gathered}
5^{\prime} \text {-GCTC - - AATC-3' } \\
:: \\
3^{\prime} \text { ' -CTAA - - CTCG-5' }
\end{gathered}
$$

An alternative maneuver would have been to exclude the terminal base at the $3^{\prime}$ end of the primer, which also would have decreased the stability of a dimer formed at the 3 ' end. However, the smaller primer might have been less effective in reverse transcription. In the case of influenza B, $100 \%$ homology was achieved without the use of a degeneracy. The primers for both influenza $A$ and $B$ appeared versatile in that they worked well in transcription and PCR with four different influenza $A$ viruses and with three different influenza B viruses.

Optimum conditions for PCR were established by titration with representative isolates contained in influenza $A$ (A/Taiwan/89) and influenza B (B/Ann Arbor/86) vaccines. As noted by others, the concentrations of $\mathrm{Mg}^{2+}$ and $\mathrm{K}^{+}$ were important variables in the assay. (13) Our findings with $\mathrm{K}^{+}$differ from those reported for an asymmetric PCR system used in sequencing. There, Taq polymerase was inhibited when the $\mathrm{K}^{+}$concentration was $\geq 75 \mathrm{~mm}^{(13)}$ Such inhibition was not noted in our system, perhaps because it was not asymmetric, was not optimized for sequencing, and had little gelatin
TABLE 1 Detection of Influenza A in Nasal Washes of 33 Patients with Symptoms of Viral Respiratory Infection

\begin{tabular}{lcc}
\hline & \multicolumn{2}{c}{ Culture } \\
\cline { 2 - 3 } PCR & positive & negative \\
\hline Positive & 13 & $2^{\mathrm{a}}$ \\
Negative & 1 & $17^{\mathrm{b}}$ \\
\hline
\end{tabular}

aPCR products in both cases were strongly reactive with the hybridization probe for influenza A.

${ }^{\mathrm{b}}$ Three patients grew rhinovirus and 2 grew respiratory syncytial virus. PCRs of all 33 washes were negative with primers specific for influenza $B$.

$(0.0011 \%)$. In fact, specific product formation in our assay actually increased in direct proportion to the $\mathrm{K}^{+}$ concentration up to the highest level tested (i.e., $115.5 \mathrm{~mm}$ ).

The sequence of the PCR product of the $\mathrm{H} 1 \mathrm{~N} 1$ isolate of influenza $\mathrm{A}$ in clinical samples was found to differ from that of the model sequence (A/Bangkok/79) by only 3 nucleotides. In contrast, the PCR product of influenza B/Ann Arbor/1/86 differed in 20 of 365 nucleotides from the model sequence $(B / L e e / 40)$. This result was not unexpected, in that a comparison of published sequences of the same region of other, more recent isolates of influenza B shows appreciable genetic drift. For example, in the database, B/Ann Arbor/1/86 differs from B/Lee/ 40 by 9 nucleotides (each confirmed in the present study) and B/Singapore/ 222/79 differs by 17 nucleotides (13 of which were confirmed in the present work).

The present assay provided typespecific identification of influenza. The primers for type A were completely nonreactive with products of influenza $B$ viruses and vice versa. Type specificity was established by the characteristic size of the PCR products on gels and by binding of type-specific probes. Type-specific identification of influenza is very important clinically because amantadine and its congeners, which are the only antimicrobials available for prophylaxis and treatment, affect only type A viruses. Typing is also important epidemiologi- 
cally because influenza $A$ is subject to major antigenic shifts and can cause pandemics while influenza $B$ causes only sporadic disease.

The present assay detected influenza in respiratory secretions stored for up to 1 year at $-20^{\circ} \mathrm{C}$. The addition of disassociation buffer for inactivation of RNases just before the samples were thawed appeared satisfactory for routine use with frozen respiratory secretions in PCR. The success of the assay with such samples suggests that respiratory secretions can be collected without disassociation buffer and stored frozen until assay. The ability of the assay to detect influenza in stored samples makes it potentially very useful for epidemiological studies and for the diagnosis of influenza in areas that lack facilities for culture.

A clinical trial to assess the sensitivity of PCR in routine clinical use showed that PCR detected influenza A in 13 of 14 patients with positive cultures for influenza $A$ and in 2 additional patients whose cultures did not grow any respiratory virus. Because of the strong bands of the products at 212 bp on gels and their strong binding of the type $A$ hybridization probe, the products appeared specific for influenza A. It seems unlikely that positive results in culture-negative samples were due to contamination of the samples during assay because controls, including nasal washes of 5 patients with respiratory infection due to other kinds of respiratory viruses, remained negative. Taken together, these results indicate that the PCR method presented here can detect influenza in frozen samples with a sensitivity comparable to culture of the fresh material.

\section{ACKNOWLEDGMENTS}

This work was supported by funds from the VA Medical Research Service. We thank Dr. Calvin Linnemann, University of Cincinnati Medical School (Cincinnati, $\mathrm{OH}$ ) for providing the bronchoalveolar lavage fluids.

A patent application has been submitted for primers and hybridization probes.

\section{REFERENCES}

1. Coonrod, J.D., P. Karathanasis, R.F. Betts, and J.C. Donofrio. 1988. Enzyme linked immunoabsorbant assay of core antigens for clinical diagnosis of influenza. J. Med. Virol. 25: 399-409.

2. Coonrod, J.D., R.F. Betts, C.C. Linnemann, and L.C. Hsu. 1987. Etiologic diagnosis of influenza A virus by enzymatic radioimmunoassay. J. Clin. Microbiol. 19: 361-365.

3. Rychlik, W., W.J. Spencer, and R.E. Rhoads. 1990. Optimization of annealing temperature for DNA amplification in vitro. Nucleic Acids Res. 18: 6409-6412.

4. Chomczynski, P. and N. Sacchi. 1987. Single-step method of RNA isolation by acid guanidinium thiocyanatephenol-chloroform extraction. Anal. Biochem. 162: 156-159.

5. Maniatis, T., E.F. Fritsch, and J. Sambrook. 1982. Southern transfer. In Molecular Cloning: A laboratory manual, pp. 382-386. Cold Spring Harbor Laboratory, Cold Spring Harbor, New York.

6. Tabor, S. 1990. 5' End labeling with T4 polynucleotide kinase. In Current protocols in molecular biology (ed. F. Ausubel, R. Brent, R.E. Kingston, D.D. Moore, J.G. Seidman, J.A. Smith, and K. Struhl), vol. 1, pp. 3.10.2-3.10.5. Wiley, New York.

7. Church, G. and W. Gilbert. 1984. Genomic sequencing. Proc. Natl. Acad. Sci. 81: 1991-1995.

8. Strauss, W.N. 1990. Hybridization with radioactive probes. In Current Protocols in Molecular Biology (ed. F. Ausubel, R. Brent, R.E. Kingston, D.D. Moore, J.G. Seidman, J.A. Smith, and K. Struhl), vol. 1, pp. 6.3.1-6.4.10 and 2.9.4-2.9.13. Wiley, New York.

9. Sebedee, S. and R. Lamb. 1989. Nucleotide sequences of influenza $A$ virus RNA segment 7: A comparison of five isolates. Nucleic Acids Res. 17: 2870.

10. Ortin, J., C. Martinez, L. del Rio, M. Davila, C. Lopez-Galindez, N. Villanveva, and E. Domingo. 1983. Evolution of the nucleotide sequence of influenza virus RNA segment 7 during drift of $\mathrm{H} 3 \mathrm{~N} 2$ subtype. Gene 23: 233-239.

11. Briedis, D., R. Lamb, and P. Chuppin. 1982. Sequence of RNA segment 7 of the influenza B virus genome: Partial amino acid homology between the membrane proteins (M1) of influenza $A$ and $B$ viruses and conservation of $a$ second open reading frame. Virology 116: $581-588$.
12. Nicolas, O. and J. Laliberte. 1991. The use of PCR for cloning of large cDNA fragments of turnip mosaic polyvirus. J. Virol. Methods 32: 57-66.

13. Innis, M., K. Myambo, D. Gelfand, and $M$. Brow. 1988. DNA sequencing with Thermus Aquaticus DNA polymerase and direct sequencing of polymerase chain reaction-amplified DNA. Proc. Natl. Acad. Sci. 85: 94369440.

Received September 21, 1991; accepted in revised form January 31, 1992. 


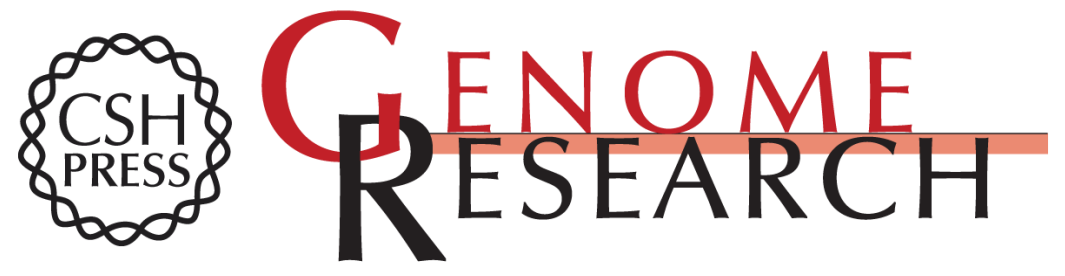

\section{Detection of influenza A and $B$ in respiratory secretions with the polymerase chain reaction.}

J C Donofrio, J D Coonrod, J N Davidson, et al.

Genome Res. 1992 1: 263-268

Access the most recent version at doi:10.1101/gr.1.4.263

References This article cites 10 articles, 2 of which can be accessed free at:

http://genome.cshlp.org/content/1/4/263.full.html\#ref-list-1

\section{License}

Email Alerting Receive free email alerts when new articles cite this article - sign up in the box at the Service top right corner of the article or click here.

\section{Affordable, Accurate Sequencing.}

To subscribe to Genome Research go to:

https://genome.cshlp.org/subscriptions 